\title{
OZONÓliSE DAS LIGNINAS ORGANOSSOLVE E KRAFT EUCALIPTO. PARTE II: CINÉTICA NOS MEIOS ÁCIDO E BÁSICO.
}

Evandro A. Nascimento e Sérgio A. L. Morais

Departamento de Química - UFU - 38400089 - Uberlândia - MG

Francisco J. T. Aquino e Dorila Piló - Veloso

Departamento de Química - UFMG - 31270901 - Belo Horizonte - MG

Recebido em 2/6/97; aceito em 4/3/98

\begin{abstract}
OZONOLYSIS OF ORGANOSOLV AND KRAFT EUCALYPTUS LIGNINS. PARTE II: KINETIC IN BASIC AND ACID MEDIA. Organosolv and kraft lignins were treated with ozone both in basic and acid media and the reaction was studied kinetically. In contrast to reported studies, ozone was more efective in basic medium. Kraft lignin was degraded faster than organosolv lignin in both media but in the basic medium the rate of reaction was very much faster than in the acid one: for kraft lignin, the observed degradation was $93 \%$ for 2 min of reaction in the basic medium and $56 \%$ for $10 \mathrm{~min}$ of reaction in the acid medium; for organosolv lignin, $47 \%$ and $25 \%$, respectively, in the same times. Higher phenolic hydroxyl groups contents increase the reaction rate.
\end{abstract}

Keywords: ozonolysis; ozone bleaching; organosolv and kraft lignins.

\section{INTRODUÇÃO}

Milhões de toneladas de polpa de celulose kraft são produzidas anualmente no Brasil. Esta polpa resulta do cozimento prolongado de cavacos de madeira com sulfeto de sódio e hidróxido de sódio, a $160^{\circ} \mathrm{C}$, e contém restos de lignina e outros produtos de reação que lhe dão uma tonalidade amarronzada. Por isso ela não pode ser utilizada imediatamente na produção de papéis mais nobres, de maior alvura. Para tanto ela necessita passar por tratamentos químicos de branqueamento que paulatinamente vão degradando a lignina residual e os outros produtos. Até a década passada os agentes alvejantes eram constituídos fundamentalmente por cloro, hipoclorito e dióxido de cloro os quais são muito eficientes mas que, infelizmente, produzem efluentes com elevada carga de compostos orgânicos clorados reconhecidamente tóxicos. Em verdade, a substituição parcial ou total do cloro e do hipoclorito por dióxido de cloro reduz significativamente a geração dos organoclorados mas mesmo assim a concentração destes produtos permanece ainda elevada nas águas residuais das indústrias de celulose. Devido a este impacto danino ao meio ambiente, a tendência mundial é substituir o cloro e derivados por compostos ecologicamente mais aceitáveis, o que vem ocorrendo ${ }^{1}$.

Atualmente as pesquisas têm dado ênfase à busca de tecnologias alternativas de branqueamento de polpas de celulose baseadas na eliminação de cloro elementar (elementar chlorine free - ECF) ou na eliminação total de cloro e derivados (totally chlorine free - TCF). A introdução de novos alvejantes (oxigênio, peróxido de hidrogênio, ozônio, perácidos, xilanases, etc.) nos processos convencionais de branqueamento de polpas de celulose já é uma realidade ${ }^{1}$. Além desses esforços, procura-se também reduzir ao máximo possível o conteúdo de lignina na polpa a ser branqueada e relativo sucesso tem sido obtido com os processos kraft modificados ${ }^{1}$.

O ozônio é provavelmente o mais importante e promissor substituto do dióxido de cloro no branqueamento de polpas de celulose devido a seu grande potencial padrão $\left(\mathrm{E}^{\mathrm{o}}=2,07 \mathrm{~V}\right.$ contra $\mathrm{E}^{\mathrm{o}}=1,56 \mathrm{~V}$ do dióxido de cloro e $\mathrm{E}^{\mathrm{o}}=1,36$ do cloro). Em soluções aquosas o elevado poder de oxidação do ozônio frente a outros oxidantes se manifesta no número de elétrons que capta, por mol, (número de equivalentes de oxidação) ao reduzir-se, como mostra a figura 1.

$$
\begin{gathered}
\mathrm{O}_{3}+6 \mathrm{H}^{+}+6 \mathrm{e} \rightarrow 3 \mathrm{H}_{2} \mathrm{O} \\
\mathrm{ClO}_{2}+4 \mathrm{H}^{+}+5 \mathrm{e} \rightarrow \mathrm{Cl}^{-}+2 \mathrm{H}_{2} \mathrm{O} \\
\mathrm{Cl}_{2}+2 \mathrm{e} \rightarrow 2 \mathrm{Cl}^{-} \\
\mathrm{ClO}^{-}+2 \mathrm{H}^{+}+2 \mathrm{e} \rightarrow \mathrm{Cl}^{-}+\mathrm{H}_{2} \mathrm{O}
\end{gathered}
$$

Figura 1. Número de equivalentes de alguns oxidantes em solução aquosa.

Esta propriedade é extremamente importante do ponto de vista econômico ${ }^{1}$ e favorece o emprego de ozônio em seqüências de branqueamento livres de cloro e derivados. Como consequiência, quase uma dezena de plantas industriais começou a utilizar o ozônio em estágios de branqueamento até 1994, contra nenhuma em 1992, confirmando a excelente adaptação do ozônio nos processos ECF e TCF ${ }^{2}$.

A molécula de ozônio pode ser representada como um híbrido de ressonância de quatro formas canônicas $(\mathrm{a}-\mathrm{d})$ vistas na figura 2. Percebe-se por esta figura que o átomo central de oxigênio é mais eletrofílico o que é confirmado pela densidade eletrônica deste átomo que alcança 5,45; a dos átomos das extremidades alcança 6,28. Embora o mecanismo de reação com ozônio ainda não esteja totalmente esclarecido, postula-se que o ataque à macromolécula de lignina, seja no anel aromático ou na cadeia lateral insaturada, se inicia pelos átomos da extremidade e este passo é o determinante da velocidade de reação ${ }^{3-4}$.

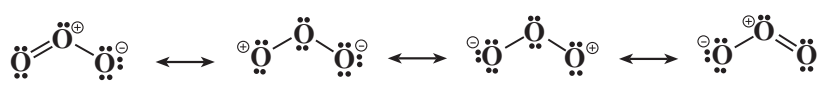

Figura 2. Estruturas canônicas do híbrido de ressonância da molécula do ozônio.

Em seguida são apresentadas reações do ozônio com a lignina relatadas na literatura as quais foram estabelecidas através de estudos da ozonólise com compostos-modelo da lignina natural e da lignina $\mathrm{kraft}^{3-13}$

A clivagem das ligações $\beta$-O-4 tem sido proposta como uma importante via inicial de degradação da lignina ${ }^{9}$ justamente porque trata-se da ligação mais abundante neste polímero. A reação de clivagem é mostrada na figura 3 . A reação característica do 
ozônio com ligações duplas pode ser vista na figura 4 e, com a lignina, estas ligações duplas podem pertencer tanto ao anel como à cadeia alifática e geram, normalmente, grupos carboxílicos. Estas reações são também importantes porque destroem a cadeia polimérica da lignina gerando fragmentos menores e mais oxigenados e, conseqüentemente, mais solúveis.

Adicionalmente podem ocorrer reações de hidroxilação dos anéis aromáticos das estruturas guaiacílicas de lignina (figura 5 ), bem como a clivagem oxidativa dos grupos metoxílicos (figura 6).

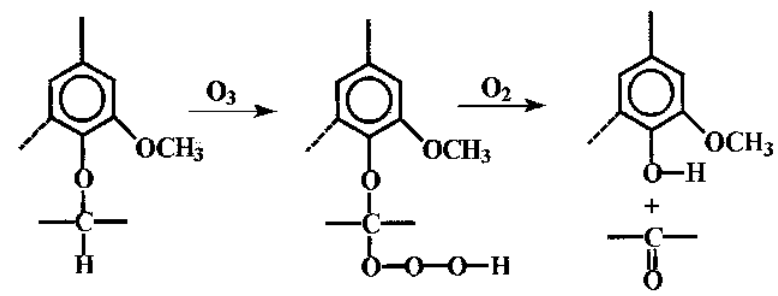

Figura 3. Oxidação das ligações $\beta-O-4$ de subestruturas de ligninas pelo ozônio ${ }^{9}$.

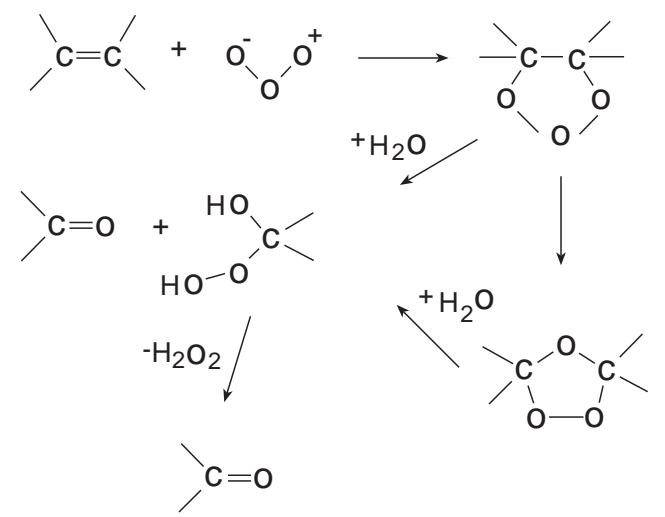

Figura 4. Clivagem da ligação dupla do anel aromático ou da cadeia lateral de ligninas pelo ozônio ${ }^{4,9}$.

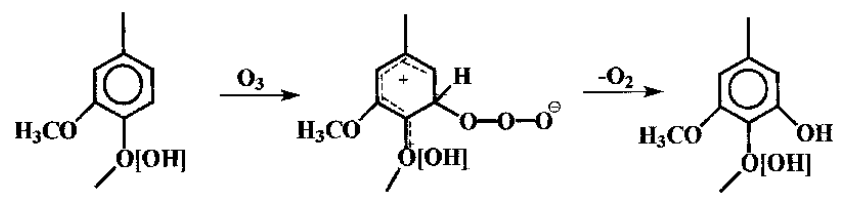

Figura 5. Hidroxilação de subestruturas guaiacílicas de ligninas pelo ozonio ${ }^{3}$.

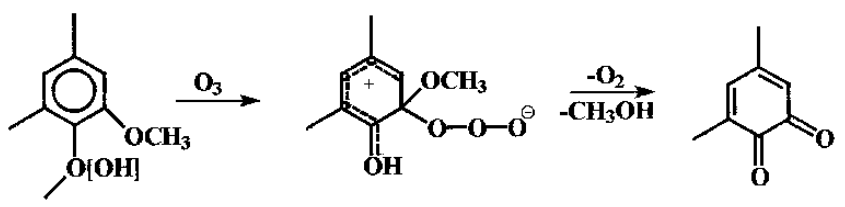

Figura 6. Clivagem oxidativa dos grupos metoxílicos de ligninas pelo ozônio ${ }^{3}$.

A formação de fragmentos radicalares a partir das estruturas fenólicas livres da macromolécula da lignina possibilita a formação de novas ligações $\mathrm{C}-\mathrm{C}$ entre os fragmentos de lignina, via acoplamento desses radicais ${ }^{10-11}$.

A ozonização das estruturas aromáticas e olefínicas de ligninas é acompanhada da formação de oxigênio molecular, além de estruturas fenólicas livres, como visto nas figuras 5 e 6. Como resultado, as subestruturas fenólicas de ligninas podem reagir muito rapidamente com esse oxigênio e/ou espécies radicalares, formando estruturas oligoméricas.
Alguns mecanismos de formação destes radicais já foram sugeridos $^{12}$. É provável que o processo comece com a abstração de um elétron do ânion fenolato, resultando na formação de fenoxi-radicais. Estes radicais podem sofrer acoplamento, resultando em estruturas bifenílicas mais complexas. Como prova, Johansson e Ljunggren ${ }^{13}$ compararam as reatividades de diferentes compostos-modelo de lignina frente ao oxigênio, em meio alcalino, e observaram a formação de novas ligações cruzadas ("crosslinks") a partir de fenoxi-radicais intermediários. Tal consideração apoia-se também nos resultados da decomposição do ozônio em meio básico.

Ainda segundo Johansson e Ljunggren ${ }^{13}$, uma representação "ideal" de estrutura de lignina para degradação com espécies oxigenadas deve possuir uma unidade monomérica fenilpropanóide formada por grupos fenólicos livres, contendo um grupo hidroxílico ou metoxílico na posição meta, bem como uma insaturação $\alpha-\beta$ na cadeia lateral.

Assim, a formação de estruturas do tipo dipropil-biguaiacol por acoplamento radicalar do propil-guaiacol é um processo indesejável já que essas novas estruturas cromóforas possuem baixa reatividade frente às espécies oxigenadas e resistirão à sua remoção nas condições típicas de branqueamento.

Condições ácidas de branqueamento são necessárias para a manutenção da estabilidade do ozônio, já que ocorrem reações de decomposição em meio alcalino (figura 7). A meia-vida do ozônio em solução de hidróxido de sódio $1 \mathrm{~N}$ é de somente 2 min. Por isso, antes de se proceder a ozonólise a polpa de celulose é acidificada.

\begin{tabular}{|c|c|c|c|c|c|c|c|}
\hline $\mathrm{O}_{3}$ & + & $\mathrm{HO}^{-}$ & $\rightarrow$ & HOO' & + & $\mathrm{O}_{2} \dot{-}$ & (1) \\
\hline $\mathrm{O}_{3}$ & + & $\mathrm{O}_{2} \stackrel{-}{-}$ & $\rightarrow$ & $\mathrm{O}_{3}^{-}$ & + & $\mathrm{O}_{2}$ & (2) \\
\hline $\mathrm{O}_{3} \stackrel{-}{-}$ & + & $\mathbf{H}^{+}$ & $\rightleftharpoons$ & $\mathrm{HO}_{3}{ }^{\circ}$ & & & (3) \\
\hline \multirow{3}{*}{$\mathrm{HO}^{\circ}$} & & $\mathrm{HO}_{3}{ }^{\circ}$ & $\rightarrow$ & HO' & + & $\mathrm{O}_{2}$ & (4) \\
\hline & + & $\mathrm{O}_{3}$ & $\rightarrow$ & $\mathrm{HO}_{4}{ }^{\circ}$ & & & (5) \\
\hline & & $\mathrm{HO}_{4}{ }^{\circ}$ & $\rightarrow$ & HOO' & + & $\mathrm{O}_{2}$ & (6) \\
\hline $\mathrm{HO}_{4}{ }^{\circ}$ & + & $\mathrm{HO}_{4}{ }^{\circ}$ & $\rightarrow$ & $\mathbf{H}_{2} \mathbf{O}_{2}$ & + & $2 \mathrm{O}_{3}$ & (7) \\
\hline $\mathrm{HO}_{4}{ }^{\circ}$ & + & $\mathrm{HO}_{3}{ }^{\circ}$ & $\rightarrow$ & $\mathrm{H}_{2} \mathrm{O}_{2}$ & + & $\mathrm{O}_{3}+\mathrm{O}_{2}$ & (8) \\
\hline
\end{tabular}

Figura 7. Reações de decomposição do ozônio em sistemas aquosos ${ }^{14}$.

O objetivo deste trabalho foi estudar a possibilidade de utilização do ozônio como um agente químico de branqueamento de polpas de celulose em baixas consistências (1-5\%) e em meio ácido. Na parte I foi estudada a degradação da lignina organossolve em meio ácido ${ }^{15}$. Nesta parte II serão apresentados os resultados do estudo cinético da ozonólise das ligninas organossolve, que é pouco degradada por ter sido extraída de cavacos de madeira com uma mistura de solventes orgânicos, e da kraft, que é mais degradada por ter sido extraída por meio da reação com sulfeto de sódio em meio alcalino e à temperatura de $160^{\circ} \mathrm{C}$. Na parte III apresentaremos os resultados do branqueamento propriamente dito das polpas organossolve e $\mathrm{kraft}^{16}$.

\section{MATERIAIS E MÉTODOS}

\section{Obtenção das ligninas organossolve e kraft}

A polpação organossolve foi feita com $50 \mathrm{~g}$ de cavacos da madeira de eucalipto absolutamente secos e $300 \mathrm{~mL}$ da mistura de ácido acético - acetato de etila - água (2:2:1) em um autoclave de $1 \mathrm{~L}$, à temperatura de $180^{\circ} \mathrm{C}$ por $3 \mathrm{~h}^{17}$. A lignina organossolve foi obtida por precipitação, com ácido clorídrico a $1 \%$, do licor negro resultante desta polpação. Depois de filtrada ela foi lavada exaustivamente com água e deixada secar a $105^{\circ} \mathrm{C}$ por 5 horas. A lignina kraft foi obtida da mesma 
maneira só que a partir do licor de polpação kraft da madeira de eucalipto. Este licor foi fornecido pela indústria CENIBRA.

\section{Ozonólise das ligninas em meio básico}

As amostras de lignina (400 mg) foram dissolvidas em 25 $\mathrm{mL}$ de solução $\mathrm{NaOH} 0,1 \mathrm{~N}$ contida em um reator tipo frasco lavador. Em seguida, uma mistura de $\mathrm{O}_{2} / \mathrm{O}_{3}$ (fluxo de 0,1 L/ min, correspondendo a $1,0 \%$ em massa de ozônio) foi borbulhada nesta solução a diferentes tempos de reação, à temperatura ambiente e sob vigorosa agitação. Foi utilizado um ozonizador da marca OREC, modelo V1. A quantidade de ozônio adicionada à mistura de reação foi calculada a partir da massa de ozônio que passou por minuto por uma amostra em branco sem lignina. Esta concentração foi determinada indiretamente por titulação iodométrica de uma solução ácida de iodeto de potássio previamente borbulhada com a mistura $\mathrm{O}_{2} /$ $\mathrm{O}_{3}$, utilizando-se uma solução de tiossulfato de sódio de concentração conhecida e amido como indicador. O ozônio não reagido com a lignina foi recolhido em solução de iodeto de potássio $5 \%$ e titulado com solução de tiossulfato de sódio. O consumo de ozônio pelas amostras de lignina foi posteriormente determinado por diferença. Em seguida, a mistura de reação foi acidificada com solução de $\mathrm{HCl} 0,5 \mathrm{~N}$ até $\mathrm{pH}$ 3. Após precipitação, as amostras ozonizadas foram filtradas, lavadas com água destilada até $\mathrm{pH}$ neutro e secas a $105^{\circ} \mathrm{C}$ por $5 \mathrm{~h}$.

\section{Ozonólise das ligninas em meio ácido}

As amostras de lignina organossolve $(400 \mathrm{mg})$ foram ozonizadas em solução de ácido acético a $70 \%$, seguindo o mesmo procedimento utilizado em meio básico.

\section{Determinação da concentração da lignina em solução}

A concentração da lignina residual foi determinada por titulação com $\mathrm{KMnO}_{4}$ tendo como referência uma curva padrão. Esta curva relacionou os volumes de $\mathrm{KMnO}_{4} 0,1 \mathrm{~N}$ necessários para oxidar soluções de concentração 1, 2, 5, 10, 20, 50 e $100 \mathrm{mg} / \mathrm{L}$ de lignina.

Esgotado o tempo de ozonólise fixado para cada experimento, o fornecimento de ozônio era interrompido e a solução titulada imediatamente com $\mathrm{KMnO}_{4}$; o volume gasto era levado à curva padrão e obtinha-se a concentração de lignina que não fora ozonizada. O resultado apresentado nas tabelas constitui a média de três experimentos.

\section{Espectroscopia no UV}

Os espectros no ultravioleta foram obtidos em um espectrofotômetro UV-VI HITACHI, modelo 2000. O branco para as amostras ozonizadas em meio básico foi solução de $\mathrm{NaOH} 0,1$ $\mathrm{N}$ e em meio ácido, solução de ácido acético a $70 \%$.

\section{RESULTADOS E DISCUSSÃO}

\section{Ozonólise em meio básico}

A tabela 1 apresenta a variação da concentração das ligninas organossolve e kraft para diferentes tempos de ozonização.

Cerca de 93\% de lignina kraft foi degradada até 2 min. A partir daí, observa-se uma diminuição na velocidade de remoção da lignina, ficando a sua concentração praticamente estacionada por volta de $0,5 \mathrm{mg} / \mathrm{L}$.

Para a lignina organossolve observa-se uma remoção mais lenta (cerca de $47 \%$ ) até 2 min de ozonização, permanecendo uma quantidade maior de lignina residual resistente à ozonólise. A partir de 5 min tem-se início uma estagnação do processo.

As diferentes reatividades frente ao ozônio apresentadas pelas duas ligninas estudadas estão seguramente relacionadas à estrutura de cada molécula e é de difícil interpretação como pode-se inferir a partir de algumas características estruturais de ambos os polímeros mostradas logo em seguida.

A lignina organossolve ${ }^{17}$ pouco se altera com o processo extrativo como pode ser comprovado pela comparação de sua fórmula mínima $\left(\mathrm{C}_{9}\right)$ com a da lignina natural do Eucalyptus grandis $\left(\mathrm{C}_{9} \mathrm{H}_{7,36} \mathrm{O}_{3,57}\left(\mathrm{OCH}_{3}\right)_{1,24}\right.$ e $\mathrm{C}_{9} \mathrm{H}_{7,90} \mathrm{O}_{2,73}\left(\mathrm{OCH}_{3}\right)_{1,50}$, respectivamente) e de sua massa molecular média em massa de (6029 e $8400 \mathrm{Da}$, respectivamente). As transformações observadas são da quebra parcial das ligações $\beta$-O-4 (que reduzem a cadeia polimérica e, portanto, reduzem a massa molecular média em massa), a perda de aproximadamente $17 \%$ de grupos metoxila, acetilação dos grupos hidroxila (observável pelo aparecimento do sinal de baixa intensidade a $\delta 170$ devido ao carbono carbonílico do grupo acetila, no espectro de RMN do ${ }^{13} \mathrm{C}$ ) e aumento da porcentagem dos grupos hidroxila fenólicos de $2,30 \%$ para $4,93 \%$. Estas mudanças fazem com que a massa da unidade $\mathrm{C}_{9}$ passe de $206 \mathrm{Da}$ na lignina natural para $211 \mathrm{Da}$ na lignina organossolve.

Por outro lado, a lignina kraft sofre grandes transformações durante o cozimento dos cavacos com sulfeto de sódio em meio básico. A composição elementar da lignina kraft do Eucalyptus grandis passa a ser: C:59,84; H:5,32; S:2,32 e O:32,52\% . O conteúdo em grupos metoxila sofre pequena variação, caindo para $17,30 \%$. Estes dados levam a fórmula mínima $\mathrm{C}_{9} \mathrm{H}_{7,41} \mathrm{O}_{3,02}\left(\mathrm{OCH}_{3}\right)_{1,10}$ (descontado o enxofre), correspondendo a uma massa de 198 Da. A massa molecular média em massa da lignina kraft de eucalipto alcançou $2865 \mathrm{Da}$ e a porcentagem de hidroxilas fenólicas 7,20\%, o que mostra o quanto as ligações $\beta$ O-4 da lignina natural são rompidas durante a polpação. Além disso, a espectroscopia de $\mathrm{RMN}$ do ${ }^{13} \mathrm{C}$ mostra que e a lignina kraft contém significativamente menos carbonos oxigenados alifáticos e anéis guaiacílicos, e mais carbonos carboxílicos do que a lignina natural ${ }^{18}$. Ainda não foi publicada uma proposta de estrutura para a lignina kraft de eucalipto e muito menos alguma proposição de como está inserido o enxofre nesta macromolécula.

Pelo exposto acima, fica difícil explicar por que o ozônio

Tabela 1. Variação da concentração das ligninas organossolve e kraft durante a ozonização em solução de $\mathrm{NaOH}, \mathrm{pH}=12$; Lo= concentração inicial de lignina.

\begin{tabular}{ccccc}
\hline Tempo (min.) & \multicolumn{2}{c}{ Lignina residual $(\mathrm{Lr}), \mathrm{mg} / \mathrm{L}$} & \multicolumn{2}{c}{$\ln (\mathrm{Lr} / \mathrm{Lo})$} \\
\hline & Organossolve & Kraft & Organossolve & Kraft \\
\hline 0,0 & 9,14 & 10,95 & 0 & $-0,489$ \\
1,0 & 5,60 & 5,47 & $-0,566$ & $-1,246$ \\
1,5 & 5,19 & 3,15 & $-0,634$ & $-2,642$ \\
2,0 & 4,85 & 0,78 & $-0,807$ & $-2,681$ \\
3,0 & 4,08 & 0,75 & $-0,995$ & $-3,009$ \\
4,0 & 3,38 & 0,54 & $-1,597$ & $-2,973$ \\
5,0 & 1,85 & 0,56 & $-1,807$ & $-3,032$ \\
10,0 & 1,50 & 0,53 & & \\
\hline
\end{tabular}


reage mais rapidamente com a lignina kraft do que com a lignina organossolve, em meio básico. Pode-se sugerir, no entanto, que os grupos hidroxila fenólicos liberados com a ruptura das ligações $\beta-O-4$, em maior número na lignina kraft, sejam um dos fatores que influenciariam a reação ao ativarem o anel aromático, facilitando o ataque eletrofílico do ozônio.

A figura 8 mostra o gráfico da variação da concentração das ligninas organossolve e kraft em função do tempo de ozonização. Por esta figura percebe-se mais claramente que a cinética de ozonização da lignina organossolve é diferente da kraft em meio básico. Em ambos os casos, porém, tem-se uma etapa inicial de reação muito rápida, onde grande parte da lignina degradável é ozonizada na etapa conhecida como "bulk delignification or bulk reaction". A "bulk reaction" dura 2 min com a lignina kraft e foi responsável pela quase totalidade de sua degradação; a lignina organossolve resiste mais à ação do ozônio, demorando 5 min para sofrer a "bulk reaction". Em ambos os casos a "residual reaction" é muito lenta como já foi dito e não compensa gastar ozônio com ela. Considerando somente a "bulk reaction", a ozonização degrada $93 \%$ da lignina kraft e $80 \%$ da lignina organossolve.

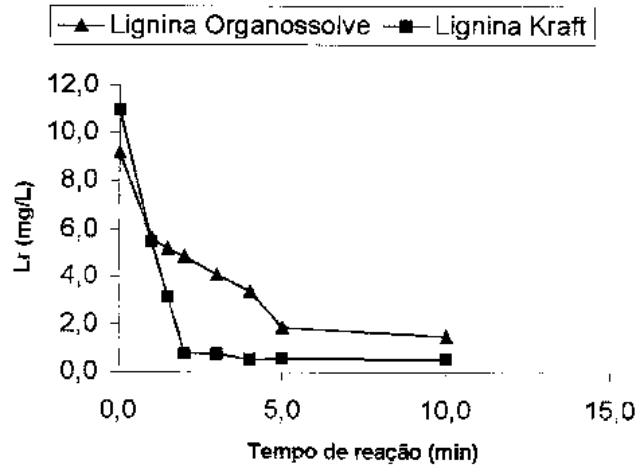

Figura 8. Variação da concentração das soluções de lignina organossolve e kraft em função do tempo de ozonização em meio básico.

O gráfico da variação do logaritmo da porcentagem de lignina residual em função do tempo de reação (figura 9) mostra que, para ambas as ligninas, a "bulk reaction" obedece a uma cinética de pseudo-primeira e que a constante de velocidade para a kraft é $9,7 \times 10^{-1} \mathrm{~min}^{-1}$ e para a organossolve é 7,3 x $10^{-2} \mathrm{~min}^{-1}$, ou seja, aproximadamente 13 vezes menor.

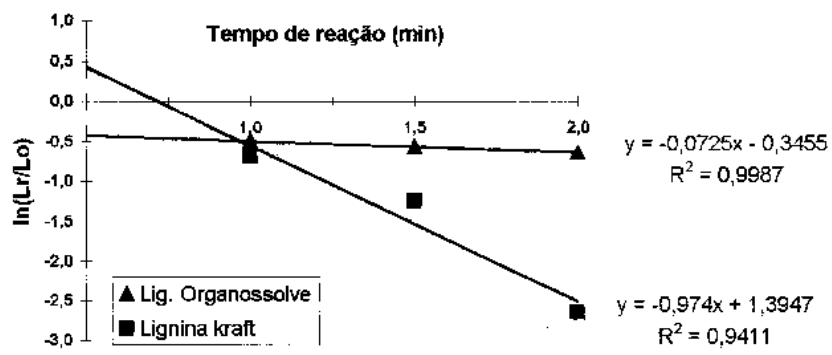

Figura 9. Cinética de deslignificação das ligninas organossolve e kraft em meio básico.
A figura 10 apresenta os espectros no ultravioleta das ligninas kraft e organossolve originais e ozonizadas. Pode-se observar que os máximos característicos de ligninas em meio básico ( $\cong 220,290$ e $360 \mathrm{~nm}$ ) praticamente desapareceram após 10 min de reação, restando porém no meio estruturas cromóforas que ainda absorvem até $400 \mathrm{~nm}$ (curvas c e d) ${ }^{19}$.

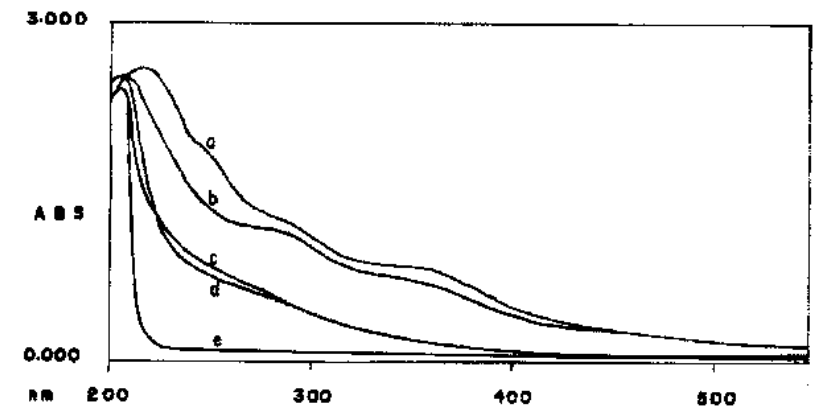

Figura 10. Espectros no ultravioleta: a: solução da lignina kraft original; b: solução da lignina organossolve original; $\boldsymbol{c}$ : lignina kraft ozonizada em meio básico por 10 min.; d: lignina organossolve ozonizada em meio básico por 10 min.; e: solução de $\mathrm{NaOH}$ ozonizada por $10 \mathrm{~min}$

A tabela 2 e a figura 11 dela derivada mostram a variação da concentração das ligninas organossolve e kraft durante a ozonólise em solução de ácido acético a $70 \%$. Elas permitem concluir que a degradação de ligninas por ozônio em meio ácido é comparativamente mais lenta que em meio básico (vide figura 8) e que a lignina kraft sofre uma degradação rápida ("bulk reaction") até $10 \mathrm{~min}$ e, após esse tempo, inicia-se a "residual reaction". Com a lignina organossolve a "bulk reaction" continua até $20 \mathrm{~min}$ de ozonólise. Transcorridos 20 de ozonólise, permanecem $49,9 \%$ da lignina organossolve sem reagir e a "bulk reaction" só foi capaz de degradar $56 \%$ da lignina kraft.

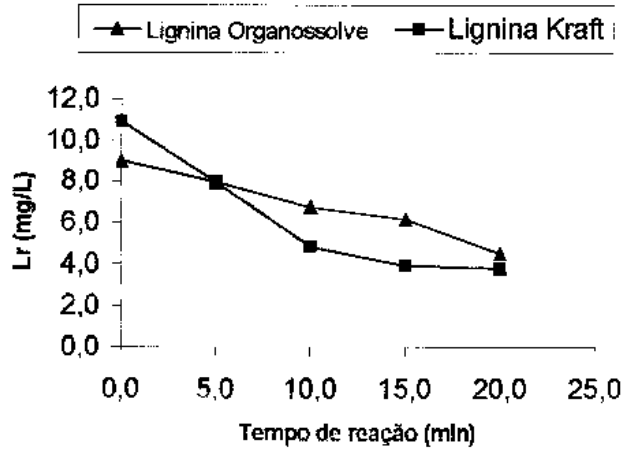

Figura 11. Variação da concentração das ligninas organossolve e kraft na ozonólise em meio ácido.

Em princípio, pelos dados acima, dever-se-ia realizar a ozonólise da lignina residual de polpas de celulose em meio básico por ser mais eficiente. Entretanto, este meio promove a formação de radicais hidroxila, superóxido, hidroperoxila, entre

Tabela 2. Variação da concentração das ligninas organossolve) e kraft durante a ozonólise em solução de ácido acético a $70 \%$.

\begin{tabular}{ccccc}
\hline Tempo (min.) & \multicolumn{2}{c}{ Lignina residual $(\mathrm{Lr}), \mathrm{mg} / \mathrm{L}$} & \multicolumn{2}{c}{$\ln (\mathrm{Lr} / \mathrm{Lo})$} \\
\hline & Organossolve & Kraft & \multicolumn{2}{c}{ Organossolve } \\
\hline 0,0 & 9,02 & 10,95 & 0 & 0 \\
5,0 & 7,95 & 7,95 & $-0,126$ & $-0,320$ \\
10,0 & 6,76 & 4,82 & $-0,288$ & $-0,820$ \\
15,0 & 6,15 & 3,90 & $-0,382$ & $-1,032$ \\
20,0 & 4,50 & 3,76 & $-0,693$ & $-1,069$ \\
\hline
\end{tabular}


outros, os quais são menos seletivos que o ozônio com respeito à lignina, degradando também a celulose ${ }^{20-21}$.

A figura 12 apresenta a cinética de deslignificação das soluções ácidas das ligninas organossolve e kraft. A partir desta figura foram calculadas as constantes de velocidade da "bulk reaction" para as duas reações estudadas: $1,6 \times 10^{-1} \mathrm{~min}^{-1}$ para a lignina organossolve e $4,1 \times 10^{-1} \mathrm{~min}^{-1}$ para a lignina kraft. Em comparação com a mesma ozonólise realizada em meio básico, nota-se que a velocidade de remoção da lignina kraft em meio básico é muito mais rápida que em meio ácido, ainda mais, a lignina organossolve degrada-se lentamente com ozônio, independentemente do $\mathrm{pH}$ do meio.

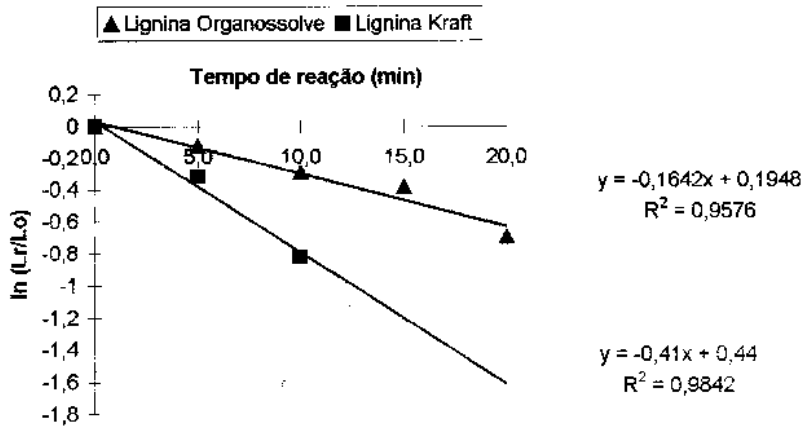

Figura 12. Cinética de deslignificação das soluções ácidas das ligninas organossolve e kraft.

Os resultados encontrados na ozonólise em meio ácido confirmam a proposição de que as hidroxilas fenólicas seriam uma das variáveis responsáveis pelo aumento da velocidade de reação, por ativarem o anel aromático frente ao ataque eletrofílico do ozônio. Com efeito, em meio ácido não ocorre a ionização do grupo fenólico, diminuindo assim a densidade eletrônica sobre o anel aromático e, conseqüentemente, a velocidade de reação.

As figuras 13 e 14 mostram os espectros no ultravioleta respectivamente das soluções das ligninas organossolve e kraft ozonizadas em meio ácido. Nas curvas a de ambas estas figuras já não aparecem os máximos a 360 nm (visíveis nas curvas a e b da figura 10 ) porquanto o meio ácido não permite a ionização dos grupos hidroxílicos fenólicos livres ${ }^{22}$. O máximo característico de ligninas a $280 \mathrm{~nm}$ (curva a) praticamente desapareceu após 20 min de reação, nos dois casos estudados. Considerando-se que nesse tempo as soluções tornaram-se praticamente incolores, e que as concentrações de lignina residual, fornecida pelo método adotado que se baseia na oxidação com $\mathrm{KMnO}_{4}$ ainda permaneciam relativamente elevadas, conclui-se que o ozônio degrada os grupos cromóforos da lignina que provocam a coloração amarelada das soluções, resultando substâncias incolores que absorvem luz de comprimento de onda até $400 \mathrm{~nm}$. Estas substâncias não reagem com ozônio mas se oxidam com permanganato, o que lança dúvida na utilização do conhecido número kappa (baseado na oxidação com $\mathrm{KMnO}_{4}$ ) para se avaliar a concentração de lignina residual de polpas de celulose após ozonólise. Segundo os resultados acima, pode-se ter uma polpa clara após a ozonólise e o número kappa ser elevado, sugerindo assim que a polpa ainda possui grupos cromofóros incolores oriundos da lignina.

\section{CONCLUSÕES}

Contrariando as espectativas, o ozônio é mais eficaz em meio básico do que em meio ácido para degradar as ligninas kraft e organossolve.

O ozônio degrada mais facilmente a lignina kraft do que a lignina organossolve, qualquer que seja o $\mathrm{pH}$ do meio. No meio básico, nos primeiros dois minutos de reação foram removidos $93 \%$ e $47 \%$ de lignina kraft e organossolve, respectivamente.

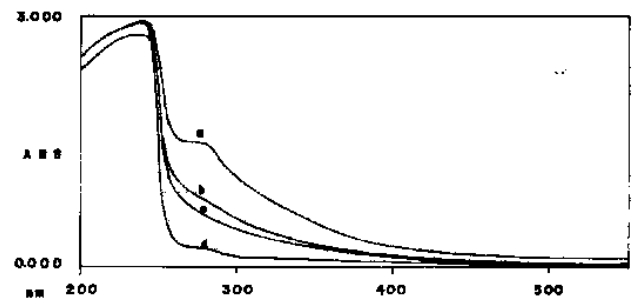

Figura 13. Espectros no ultravioleta: a: solução de lignina organossolve original; $\boldsymbol{b}$ : lignina kraft ozonizada em solução de ácido acético a $70 \%$ por 10 min.; $c$ : lignina kraft ozonizada em solução de ácido acético a $70 \%$ por 20 min.; d: solução de ácido acético a $70 \%$ ozonizada por $10 \mathrm{~min}$.

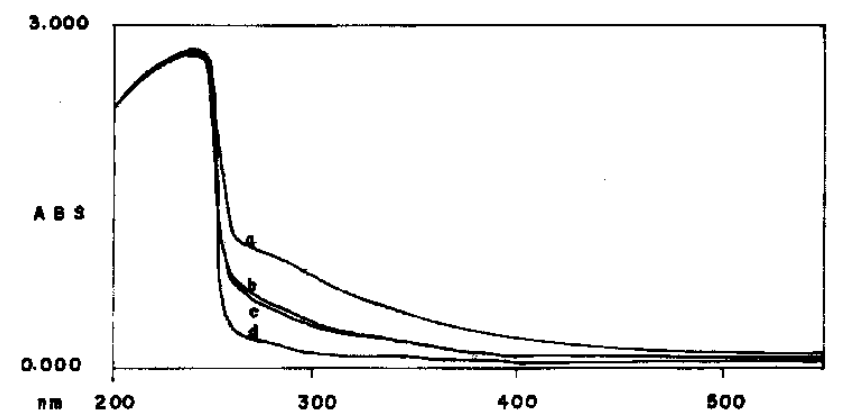

Figura 14. Espectros no ultravioleta: a: solução de lignina organossolve original; $\boldsymbol{b}$ : lignina organossolve ozonizada em solução de ácido acético a $70 \%$ por 10 min.; c: lignina organossolve ozonizada em solução de ácido acético $70 \%$ por 20 min.; $d$ : solução de ácido acético a $70 \%$ ozonizada por $20 \mathrm{~min}$.

No meio ácido, tanto a lignina kraft como a organossolve se degradam lentamente com ozônio pois, em 10 minutos de reação, somente $56 \%$ e $25 \%$, respectivamente, delas foram oxidados.

Os resultados acima indicam que ligninas que possuem maior conteúdo em grupos hidroxila fenólicos são mais sucetíveis de serem degradadas com ozônio.

$\mathrm{Na}$ ozonólise de ligninas são oxidados grupos cromóforos coloridos mas formam-se ou permanecem na sua estrutura substâncias cromóforas incolores que absorvem até $400 \mathrm{~nm}$ e que resistem à oxidação com ozônio, mas não com $\mathrm{KMnO}_{4}$. Esta constatação lança dúvidas sobre a exatidão de se empregar o número kappa como índice de avaliação da concentração de lignina residual em polpas de celulose após ozonólises.

\section{REFERÊNCIAS}

1. Grundelius, N. R.; Tappi J. 1993, 76, 133.

2. McDonough, T. J.; Tappi J. 1995, 78, 55.

3. Gierer, J.; Wood Sci. Technol. 1986, 20, 1.

4. Gierer, J.; Holzforschung 1997, 51, 34.

5. Yoshigawa, N.; Sagiya, S.; Yokota, S.; Idei, T.; Holzforschung 1996, 50, 31.

6. Puri, S. C.; Anaud, S. M.; Cell. Chem. Technol. 1986, 20, 535.

7. Kratzl, K.; Clauss, P.; Reichel, G.; Tappi J. 1976, 59, 86.

8. Elder, T.; Holzforschung 1997, 50, 47.

9. Gratzl, J. S.; Das Papier 1992, Heft 10A, V1-V8.

10. Patt, R.; Kordsachia, O.; Holzforschung 1991, 45 (Suppl.), 87.

11. Smith, D.; Dimmel, D. R.; J. Wood Chem. Technol. 1994, 14, 279.

12. Smith, D.; Dimmel, D. R.; J. Wood Chem. Technol. 1994, 14, 297.

13. Kang G.; Zhang, Y.; Ni, Y.; Heiningen, A. R. P.; J. Wood Chem. Technol. 1995, 15, 413.

14. Johansson, E.; Ljunggren, S.; J. Wood Chem. Technol. 1991, 14, 507.

15. Nascimento, E. A.; Morais, S. A. L.; Aquino, F. J. T.; Piló Veloso, D.; Proceedings of the Fourth Brazilian 
Symposium on the Chemistry of Lignins and Other Wood Components, Recife, 1995, p. 198.

16. Nascimento, E. A.; Morais, S. A. L.; Aquino, F. J. T.; Piló Veloso, D.; O Papel 1998, 59, 52.

17. Terrones, M.G.H.; Piló-Veloso, D.; Nascimento, E. A.; Livro de Resumos do V Encontro Regional da Sociedade Brasileira de Química - MG, Ouro Preto, 1991, 131.

18. Nascimento, E. A.; Morais, S. A. L.; Pilo-Veloso, D.; Menezes, S. M. C.; J. Braz. Chem. Soc. 1994, 5, 5.
19. Matsumoto, Y.; Ishizu, A.; Nakano, J.; Holzforschung 1986, 40(Suppl.), 81.

20. Yasumoto, M.; Matsumoto, Y.; J. Wood Chem. Technol. 1996, 16, 95.

21. Kishimoto, T.; Nakatsubo, F.; Holzforschung 1996, 50, 372.

22. Goldschmidt, O.; Ultraviolet Spectra, em Lignins: Occurrence, Formation, Structure and Reactions. Ed. K. V. Sarkanen and C. H. Ludwig, Wiley-Interscience, New York, 1971, p. 256. 